We thank Messrs. Ciba Ltd., Basle, for a supply of aldosterone.

$$
\begin{aligned}
& \text { V. VAN DER SchyFF } \\
& \text { H. ZWARENSTEIN }
\end{aligned}
$$

Department of Physiology and Pharmacology, University of Cape Town.

${ }^{1}$ Sapeika, N., S. Afr. J. Med. Sci., 8, 115 (1943).

2 Burgers, A. C. J., and Zwarenstein, H., Nature, 175, 687 (1955).

\section{Distribution of Taste Sensitivity for Phenylthiocarbamide in Yugoslavia}

Investigations into taste sensitivity for bitter as a particular hereditary characteristic in man have found their practical application in human, that is, population genetics. Phenylthiocarbamide (PTC) has been found the most reliable among the bitter substances used for discrimination between sensitive persons and insensitive. We believe that of the different methods described ${ }^{1-3}$ the most advantageous one is that of Harris and Kalmus ${ }^{4 \rightarrow 7}$. In addition to the testing and checking of modes of heredity, the establishment of frequency of tasters and nontasters, a relation between the sensitivity for PTC and the thyroid diseases has been noted ${ }^{7,8}$. Recently there seem to have been new developments in the interpretation of this relation'.

The sensitivity for bitter in certain other conditions and circumstances is also being tested ${ }^{10,11}$.

However, all work of this kind is based on the data regarding the distribution of tasters and non-tasters in a healthy population of a certain age. We have tested $\mathbf{4 0 6}$ students in the Medical Faculty in Zagreb. The average age was twenty-one years, with equal proportion of sexes (male 201, female 205).

The method used was that of Harris and Kalmus ${ }^{4-7}$. The results are shown in the Table 1. From there it can be seen that sensitivity lies between the fourth and the fifth solution, 66.99 per cent of the tested persons are tasters, and 33.01 per cent are non-tasters, without a significant difference between the sexes. Although the result is within the frequency limits known in some European populations, the percentage of non-tasters is higher than even in the younger persons tested in Yugoslavia ${ }^{12}$. The analysis of the material shown, with regard to the place of birth of persons, shows an increased frequency of non-tasters among people from the area along the Adriatic coast. This has already been noted in the course of other work ${ }^{13}$. According to this analysis the frequency of non-tasters would be lower in the eastern parts of
Yugoslavia. This will be the subject of further work.

\section{Department of Biology, Medical Faculty,}

University of Zagreb.

${ }^{1}$ Race, R., and Sanger, R., Blood Groups in Man (Blackwell Sci. Publications, Oxford, 1958).

a Klein, H., Deutsch. Z, gerichtl. Med., 41, 83 (1952).

a Popielski, B., Pol. tygod. lek., 11, 2 (1956).

- Harris, H., and Kalmus, H.. Ann. Eugen., 15, 24, 32 (1950).

' Kalmus, H., Biolog. Aff., 22, 1 (1959).

- Kalmus, H. (personal communication).

? Harris, H., Kalmus, H., and Trotter, W. R., Lancet, ii, 1038 (1949).

- Kitchin, F. D., et al., Brit. Med. J., i, 1069 (1959).

- Fischer, R., J. Hered., 51, 182 (1960).

${ }^{10}$ Fischer, R., and Griffin, F., Experientia, 17, 36 (1961).

"Fischer, R., Griffin, F., England, S., and Garn, S. M., Nature, 191, 1328 (1931).

${ }^{12}$ Grünwald, P., and Pfeifer, S., Lij. vje8., 84, 27 (1962).

${ }_{13}$ Pfeifer, S., and Grünwald, P., Jugosl. simp. end. gušavosti, 267 (1960).

\section{PATHOLOGY}

\section{Interaction between Epithelial and \\ Mesodermal Elements in Anthramine- induced Tumours of the Rat}

IN a group of tumours arising in rat skin painted with 2-anthramine I have observed two examples of a compound tumour different in type from those described in previous similar experiments ${ }^{1-3}$. Their essential feature is that a sarcoma forms the stroma of an epithelial tumour. The natural history shows that the carcinoma and the sarcoma begin as separate growths and unite by collision. As a result the cytology and pattern of growth of the two elements are altered; the detail of the changes throws light on the relationship between epithelium and connective tissue, as well as on the process of carcinomatous invasion.

Twelve August rats, six weeks old, were painted twice weekly for 40 weeks with a 1 per cent solution in acetone of 2-anthramine (Aldrich Chemical Co., Inc., Wisconsin) using Lennox's method ${ }^{2}$. At each painting $0.2-0.3 \mathrm{ml}$. was applied. By the fortieth week the two rats concerned in this communication showed a number of pearly tumours $0.5-1.0 \mathrm{~mm}$. in diameter studded over the almost hairless painted area on the back.

These tumours, microscopically basal-cell carcinomata, grew slowly for some weeks. Then in each rat a firm vascular dermal nodule developed which grew very rapidly, undermining several epidermal tumours

\begin{tabular}{|c|c|c|c|c|c|c|c|c|c|c|c|c|c|c|c|}
\hline \multirow[t]{3}{*}{$n=406$} & \multicolumn{14}{|c|}{ PTC solution No. } & \multirow{4}{*}{ Total } \\
\hline & $<1$ & 1 & 2 & 3 & 4 & 5 & 6 & 7 & 8 & 9 & 10 & 11 & 12 & 13 & \\
\hline & \multicolumn{5}{|c|}{ Non-tasters } & \multicolumn{9}{|c|}{ Tasters } & \\
\hline Males & 22 & 30 & 9 & 4 & 3 & 2 & 5 & 10 & 35 & 38 & 37 & 4 & 1 & 1 & \\
\hline Abs. & \multicolumn{5}{|c|}{68} & \multicolumn{9}{|c|}{133} & 201 \\
\hline Percentage & \multicolumn{5}{|c|}{$33 \cdot 83$} & \multicolumn{9}{|c|}{$66 \cdot 17$} & $49 \cdot 57$ \\
\hline Females & 14 & 24 & 21 & 5 & 2 & 3 & 3 & 11 & 28 & 48 & 36 & 9 & 1 & - & \\
\hline Abs. & \multicolumn{5}{|c|}{66} & \multicolumn{9}{|c|}{139} & 205 \\
\hline Percentage & \multicolumn{5}{|c|}{$32 \cdot 20$} & \multicolumn{9}{|c|}{$67 \cdot 80$} & $50 \cdot 49$ \\
\hline Total & \multicolumn{5}{|c|}{134} & \multicolumn{9}{|c|}{272} & 406 \\
\hline Percentage & \multicolumn{5}{|c|}{$33 \cdot 01$} & \multicolumn{9}{|c|}{66.99} & $100 \cdot 00$ \\
\hline
\end{tabular}

Table 1. The Frequency of PTC Thresholds among 201 Male and 205 Female Stodents 